Check for updates

Cite this: RSC Adv., 2019, 9, 15966

\title{
An efficient and recyclable nanocatalyst for the green and rapid synthesis of biologically active polysubstituted pyrroles and 1,2,4,5- tetrasubstituted imidazole derivatives $\uparrow$
}

\begin{abstract}
Myo Thwin, (D) a Boshra Mahmoudi, ${ }^{\text {b }}$ Olga A. Ivaschuk ${ }^{c}$ and Qahtan A. Yousif*d
An effective process for the green and rapid synthesis of biologically active polysubstituted pyrroles and 1,2,4,5-tetrasubstituted imidazoles derivatives using Cuaimine/ $\mathrm{Fe}_{3} \mathrm{O}_{4} \mathrm{MNPs}$ catalyst under solvent-free conditions is explained. This catalyst showed high reactivity for the synthesis of a set of different derivatives of polysubstituted pyrroles and 1,2,4,5-tetrasubstituted imidazole derivatives under appropriate reaction conditions and short times. Moreover, the catalyst was also recycled and reused for six runs with no considerable reduction in reactivity and yields. Compared to the reported procedures, this method consistently demonstrates the advantages of low catalyst loading, short reaction times, easy separation and purification of the products, high yields, and high recoverability and recoverability of the catalyst.
\end{abstract}

Received 27th March 2019

DOI: 10.1039/c9ra02325a

rsc.li/rsc-advances

insensitivity, and low toxicity are the other factors that have attracted more attention of scientists to these nanoscale materials. $^{5-9}$

Poly substituted imidazoles are one of the core structural Recently, studies for finding separable and reusable nanocatalysts are seeing rapid progress in chemistry, especially in modern catalysis research. The immobilization of organic and inorganic functional groups on heterogeneous supports is in fact an effective process to achieve this goal. ${ }^{1}$ Nowadays, compared to the typical separation, magnetic separation is receiving more attention due to activity as a highly efficient and rapid separation procedure for products and catalysts. ${ }^{2}$ Magnetic nanoparticles (MNPs) have unique physical and chemical features such as large surface area per weight that causes these materials to act as supports of homogeneous catalysts or heterogeneous promoters for catalytic reactions. The functionalized magnetic nanoparticles can be simply isolated from the reaction solution by an appropriate external magnetic field, without any tedious workup procedures, which reduces the catalyst loss during separation. ${ }^{3,4}$ In addition, magnetic-supported catalysts can be recovered several times with no considerable reduction in their initial activity. High coercivity, greater selectivity, environmental friendliness, noncorrosive nature, operational simplicity, moisture

${ }^{a}$ Yangon Technological University, Myanmar

${ }^{b}$ Research Center, Sulaimani Polytechnic University, Sulaimani 46001, Kurdistan Region, Iraq

${ }^{\circ}$ Belgorod National Research University, Belgorod, Russia

${ }^{d}$ University of Al-Qadisiyah, College of Science, Department of Chemistry, Republic of Iraq. E-mail: Qahtan.Adnan@qu.edu.iq; Tel: +9647813112362

$\dagger$ Electronic supplementary information (ESI) available. See DOI: skeleton in many key molecules that have attracted considerable interest because of their biological activities such as histidine, histamine, and biotin. ${ }^{10-12}$ These were firstly prepared by via cyclocondensation reaction between 1,2-dicarbonyl compounds, different aldehydes, and a nitrogen resource. ${ }^{13,14} \mathrm{~A}$ variety of catalysts in the papers following this method have been reported. ${ }^{15-22}$ Although most of these synthetic approaches provide an improvement in the production of the above mentioned heterocyclic compounds, many of these procedures suffer from one or more drawbacks like applying dangerous organic solvents and costly reagents, harsh reaction conditions, difficult and complex work-up and purification, considerable values of waste ingredients, use of toxic reagents and nonrecoverability of the catalyst as well as long reaction time and low efficiencies. ${ }^{23,24}$ Consequently, the improvement of easy, effective, and mild procedures with easily separable and reusable novel catalysts to overcome these shortcomings.

Pyrroles, as an important class of N-heterocyclic derivatives and significant building blocks, are one of the most important groups of heterocyclic compounds that have attracted considerable interest in organic production as well as in the drug exploration. They have been extensively utilized due to their promising pharmacological and therapeutic activities such as antianginal, antitumor antifungal, anti-oxidant, antibacterial, and anti-inflammatory. ${ }^{25}$ Moreover, polysubstituted pyrroles owing to their enormous importance exhibited other medicinal 
applications. Because of the aforementioned merits of the polysubstituted pyrroles, to date various approaches have been improved to synthesize these kinds of heterocyclic compounds. These were synthesized through Paal-Knorr condensation reaction, Knorr reaction and Hantzsch reaction. ${ }^{26}$ Herein we decided to study the preparation of polysubstituted pyrrole derivatives with various substituents from the reaction of aromatic aldehydes, ethyl acetoacetate, nitromethane and aniline under solvent-free conditions using $\mathrm{Cu@imine/} / \mathrm{Fe}_{3} \mathrm{O}_{4}$ MNPs as a new, eco-friendly, reusable and promising heterogeneous nanocatalyst. Although numerous methods have been utilized for the preparation of polysubstituted pyrrole derivatives, some of these strategies suffer from disadvantages such as use of high temperature, the need for excess amounts of the catalyst, long reaction times, and need for microwave or ultrasound irradiation. Therefore, it is necessary to develop an improved strategy for the preparation of polysubstituted pyrrole derivatives under mild reaction conditions.

\section{Experimental}

\section{General}

All the pure chemical substances were prepared from Fluka, Aldrich, and Merck chemical companies and applied with no further purification. Melting points of the substrate were measured with Electrothermal-9100 apparatus and uncorrected. Fourier transform infrared (FT-IR) spectra were recorded with a PerkinElmer PXI spectrometer in $\mathrm{KBr}$ wafers. X-ray diffraction (XRD) patterns of samples were taken on a Siemens D-5000 Xray diffractometer (Germany) with $\mathrm{Cu} \mathrm{K} \alpha$ radiation. Magnetic susceptibility measurements were measured by a vibrating sample magnetometry (VSM; Lake Shore 7200 at $300 \mathrm{kVsm}$ ). Thermogravimetric analysis was examined by a PerkinElmer instrument under nitrogen atmosphere at a heating rate of $10{ }^{\circ} \mathrm{C} \mathrm{min}^{-1}$. Scanning electron microscope (SEM) images were recorded with a SEM-LEO 1430VP instrument. The chemical composition of synthesized nanoparticles was obtained with an energy dispersive X-ray spectroscopy (EDX) (ESEM, Philips, and XL30).

\section{Catalyst synthesis}

Preparation of $\mathrm{Fe}_{3} \mathbf{O}_{4}$. The magnetite nanoparticles were synthesized based on the reported chemical co-precipitation method, and the detailed process has been described hereinafter. Briefly, $5.4 \mathrm{~g}$ of $\mathrm{FeCl}_{3} \cdot 6 \mathrm{H}_{2} \mathrm{O}$ and $2 \mathrm{~g}$ of $\mathrm{FeCl}_{2} \cdot 4 \mathrm{H}_{2} \mathrm{O}$ were dissolved in $40 \mathrm{~mL}$ of distilled water followed by adding $0.9 \mathrm{~mL}$ of concentrated $\mathrm{HCl}$ in a three-necked bottom $(250 \mathrm{~mL})$ under vigorous agitating and nitrogen protection. Next, $250 \mathrm{~mL}$ of 1.5 $\mathrm{M} \mathrm{NaOH}$ solution was dropped into the resultant mixture in the absence of temperature under intense mechanical stirring. In the last step, the attained magnetic nanoparticles were isolated using a powerful magnet and rinsed several times with $200 \mathrm{~mL}$ deionized water. Eventually, the $\mathrm{Fe}_{3} \mathrm{O}_{4}$ nanoparticles dried under vacuum at $40{ }^{\circ} \mathrm{C}$ for $24 \mathrm{~h}$.

Preparation of the $\mathrm{Fe}_{3} \mathrm{O}_{4} @ A P T E S .1 \mathrm{~g}$ of $\mathrm{Fe}_{3} \mathrm{O}_{4}$ nanoparticles was dispersed poured in $50 \mathrm{~mL}$ dry toluene by ultrasonic vibration; then, $2 \mathrm{~mL}$ of aminopropyltriethoxysilane (APTES) was added, and the obtained solution was mechanically agitated for $24 \mathrm{~h}$ under reflux conditions. At the end of the reaction, the $\mathrm{Fe}_{3} \mathrm{O}_{4} @ A P T E S$ nanoparticles were recovered from the solution using an external magnet, washed with deionized water and anhydrous ethanol to eliminate any unreacted chemicals, and dried under vacuum oven.

Preparation of the $\mathrm{Fe}_{3} \mathrm{O}_{4} @ A P T E S / A M T B A$. To connect of 4(4-amino-5-mercapto-4H-[1,2,4]H-1,2,4 triazol-3-yl)-benzoic acid (AMTBA) to the $\mathrm{NH}_{2}$ functional group on the surface $\mathrm{Fe}_{3} \mathrm{O}_{4}$ @APTES nanoparticles, dried $\mathrm{Fe}_{3} \mathrm{O}_{4}$ @APTES ( $2 \mathrm{~g}$ ) was poured in ethanol $(100 \mathrm{~mL})$ in a $250 \mathrm{~mL}$ round-bottom flask and then AMTBA (4 mmol) was poured in to this solution under dry nitrogen atmosphere. The reaction mixture was refluxed for $24 \mathrm{~h}$ and after that $\mathrm{Fe}_{3} \mathrm{O}_{4} @ A P T E S / A M T B A$ was separated by using an external magnet, washed thoroughly several times with ethanol and deionized water to remove the unreacted reagents, and finally dried at $80^{\circ} \mathrm{C}$ in a vacuum oven.

Preparation of the imine@ $\mathrm{Fe}_{3} \mathrm{O}_{4}$ MNPs. To prepare imine@ $\mathrm{Fe}_{3} \mathrm{O}_{4}$ MNPs, $2 \mathrm{~g}$ of $\mathrm{Fe}_{3} \mathrm{O}_{4}$ @APTES/AMTBA was poured in $20 \mathrm{~mL}$ of dry $\mathrm{CH}_{2} \mathrm{Cl}_{2}$ for $30 \mathrm{~min}$ using ultrasonication. After that, $4 \mathrm{mmol}$ of 2 -formylpyridine was added to the reaction solution and the obtained mixture was refluxed for $8 \mathrm{~h}$. Finally, these precipitates were isolated using an external magnetic field, washed with $20 \mathrm{~mL}$ of water to eliminate the unreacted residue of the 2 -formylpyridine, and next dried in a vacuum oven.

Preparation of $\mathrm{Cu} @ i m i n e / \mathrm{Fe}_{3} \mathrm{O}_{4}$ MNPs. $2 \mathrm{~g}$ of imine@ $\mathrm{Fe}_{3} \mathrm{O}_{4}$ MNPs was suspended in $50 \mathrm{~mL}$ of $\mathrm{CH}_{2} \mathrm{Cl}_{2}$ under a nitrogen atmosphere. Thereafter, $\mathrm{CuCl}_{2}(0.5 \mathrm{mmol})$ was added to the reaction solution, and agitated for $24 \mathrm{~h}$. After $24 \mathrm{~h}$, the sediment formed was isolated by a strong magnet, rinsed twice with ethanol $(15 \mathrm{~mL})$ to remove unreacted metal precursors and dried under the reduced pressure to obtain a pure product. All stages of the $\mathrm{Cu} @ i m i n e / \mathrm{Fe}_{3} \mathrm{O}_{4}$ MNPs synthesis are demonstrated in Scheme 1.

\section{Results and discussion}

\section{Catalyst characterization}

FTIR analysis of $\mathrm{Cu} @ i m i n e / \mathrm{Fe}_{3} \mathrm{O}_{4}$ MNPs. The infrared spectra corresponding to the $\mathrm{Fe}_{3} \mathrm{O}_{4}$ and $\mathrm{Cu} @ i m i n e / \mathrm{Fe}_{3} \mathrm{O}_{4}$ MNPs samples in the area of $400-4000 \mathrm{~cm}^{-1}$ are demonstrated in Fig. 1. The bands at $586 \mathrm{~cm}^{-1}$ in the $\mathrm{Fe}_{3} \mathrm{O}_{4}$ are associated to the stretching vibration for the $\mathrm{Fe}-\mathrm{O}$ bond while the absorption peak at the $3405 \mathrm{~cm}^{-1}$ region can be dedicated to the water molecule $\mathrm{OH}$ stretching modes. Also, the absorption peaks at $1617 \mathrm{~cm}^{-1}$ is related to the bending vibrations of the water molecule $\mathrm{HO}-\mathrm{H}$ bonds. In the FTIR spectrum of $\mathrm{Cu@imine/}$ $\mathrm{Fe}_{3} \mathrm{O}_{4}$ MNPs catalyst, the bands between 1400-1600 $\mathrm{cm}^{-1}$ and the absorption peaks at $1045 \mathrm{~cm}^{-1}$ region can be respectively attributed to the $\mathrm{C}=\mathrm{C}$ and $\mathrm{Si}-\mathrm{O}$ groups. The bands at 1635 , 2584 and $2987 \mathrm{~cm}^{-1}$ have been attributed to $\mathrm{C}=\mathrm{N}, \mathrm{S}-\mathrm{H}$ and $\mathrm{C}-\mathrm{H}$ stretching vibrations, respectively.

Thermal analysis of $\mathrm{Cu}$ (aimine/ $\mathrm{Fe}_{3} \mathrm{O}_{4}$ MNPs. TGA curves of $\mathrm{Fe}_{3} \mathrm{O}_{4}, \mathrm{Fe}_{3} \mathrm{O}_{4} @ A P T E S, \mathrm{Cu} @ i m i n e / \mathrm{Fe}_{3} \mathrm{O}_{4}$ MNPs was also investigated by thermogravimetric analyzer (Fig. 2). The weight loss 

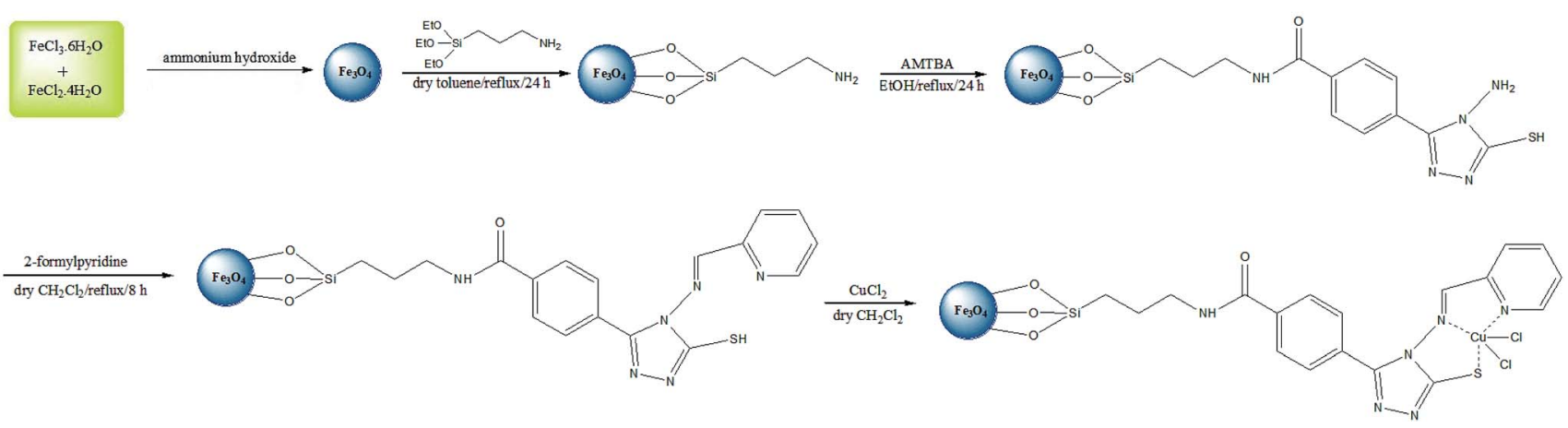

Scheme 1 All steps of the Cuaimine/ $/ \mathrm{Fe}_{3} \mathrm{O}_{4}$ MNPs synthesis.

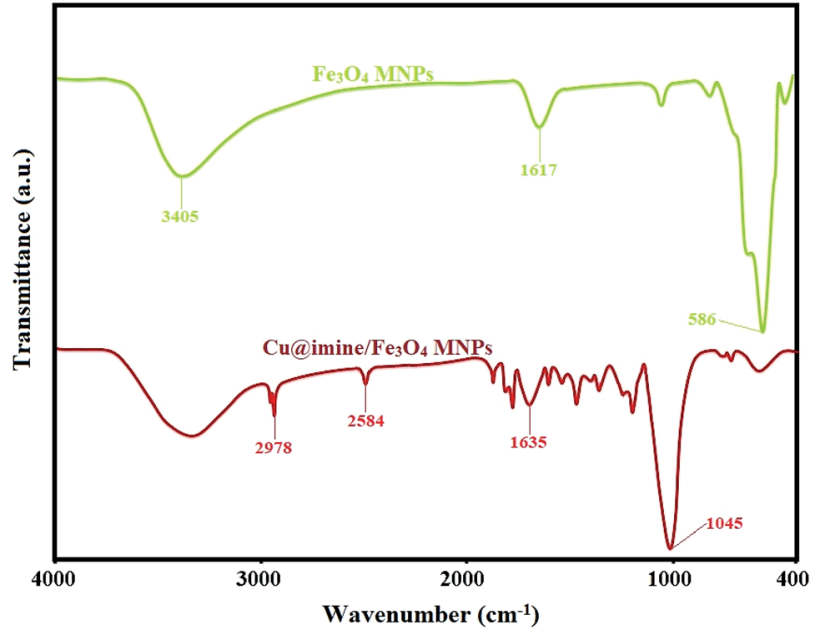

Fig. 1 FT-IR spectra of $\mathrm{Fe}_{3} \mathrm{O}_{4}$ and Cu@imine/ $/ \mathrm{Fe}_{3} \mathrm{O}_{4} \mathrm{MNPs}$.

due to evaporation of physically adsorbed $\mathrm{H}_{2} \mathrm{O}$ molecules in the temperature range below $220{ }^{\circ} \mathrm{C}$ was observed for all samples. Two weight loss stages were observed in thermogram for

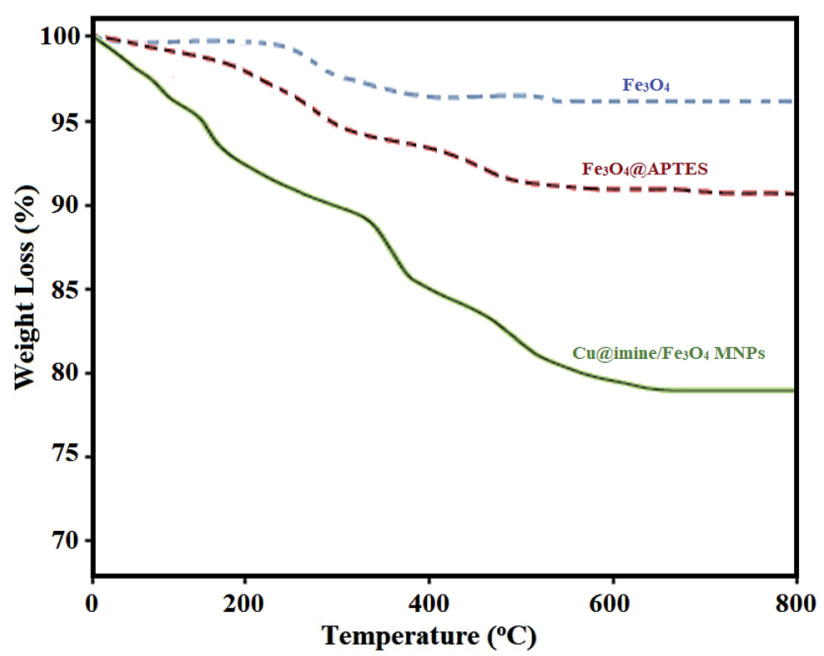

Fig. 2 TGA thermogram of $\mathrm{Fe}_{3} \mathrm{O}_{4}, \mathrm{Fe}_{3} \mathrm{O}_{4}$ (APTES, Cu@imine/ $/ \mathrm{Fe}_{3} \mathrm{O}_{4}$ MNPs.
$\mathrm{Fe}_{3} \mathrm{O}_{4} @$ @PTES, one below $200{ }^{\circ} \mathrm{C}$ which can be related to evaporating water from the MNPs surface; however the other one up to $430{ }^{\circ} \mathrm{C}$ was ascribed to the decomposition of APTES. $\mathrm{Cu} @ i m i n e / \mathrm{Fe}_{3} \mathrm{O}_{4}$ MNPs have three weight loss stages; the first weight loss up to $180^{\circ} \mathrm{C}$, which is related to evaporation of $\mathrm{H}_{2} \mathrm{O}$ molecules connected to the MNPs surface. The second and third weight loss up to 370 and $520^{\circ} \mathrm{C}$, respectively, associated to the decomposition of functionalized groups on MNPs surface. These weight losses exhibits the existence of functional groups grafted to the MNPs surface.

VSM analysis of $\mathrm{Cu} @ i m i n e / \mathrm{Fe}_{3} \mathrm{O}_{4}$ MNPs. Fig. 3 shows the magnetization measurements of $\mathrm{Fe}_{3} \mathrm{O}_{4}$ MNPs and $\mathrm{Cu@imine/}$ $\mathrm{Fe}_{3} \mathrm{O}_{4}$ MNPs, determined by VSM technique. The saturation magnetization $\left(M_{\mathrm{s}}\right)$ is observed to be $35.94 \mathrm{emu} \mathrm{g}^{-1}$ for $\mathrm{Cu} @ \mathrm{i}-$ mine/ $\mathrm{Fe}_{3} \mathrm{O}_{4}$ MNPs, less than the $\mathrm{Fe}_{3} \mathrm{O}_{4}$ MNPs (62.59 emu g ${ }^{-1}$ ). This difference suggests that functional groups are attached on the surface of $\mathrm{Fe}_{3} \mathrm{O}_{4}$ nanoparticles.

XRD analysis of $\mathbf{C u @ i m i n e ~} / \mathrm{Fe}_{3} \mathbf{O}_{\mathbf{4}}$ MNPs. The XRD patterns corresponding to the synthesized $\mathrm{Fe}_{3} \mathrm{O}_{4}$, imine@ $\mathrm{Fe}_{3} \mathrm{O}_{4} \mathrm{MNPs}$, $\mathrm{Cu} @ i m i n e / \mathrm{Fe}_{3} \mathrm{O}_{4}$ MNPs are shown in Fig. 4. The characteristic broad diffraction peaks shown in high-angle XRD pattern can be corresponded to cubic spinel magnetite $\mathrm{Fe}_{3} \mathrm{O}_{4}$ structure, which shows diffraction peaks, corresponding to (220), (311), (400), (422), (511) and (440). The relative intensities and position of imine@ $\mathrm{Fe}_{3} \mathrm{O}_{4} \mathrm{MNPs}$ and $\mathrm{Cu} @ i m i n e / \mathrm{Fe}_{3} \mathrm{O}_{4}$ MNPs peaks agree well with the $\mathrm{Fe}_{3} \mathrm{O}_{4}$ MNPs, representing retention of the crystalline cubic spinel structure over immobilization of $\mathrm{Fe}_{3} \mathrm{O}_{4}$ MNPs.

EDX analysis of $\mathrm{Cu} @ i m i n e / \mathrm{Fe}_{3} \mathrm{O}_{4}$ MNPs. Based on the EDX spectrum (Fig. 5), the existence of copper in the $\mathrm{Cu@imine/}$ $\mathrm{Fe}_{3} \mathrm{O}_{4}$ MNPs catalyst structure represents that copper was coordinates to the functional groups of imine@ $\mathrm{Fe}_{3} \mathrm{O}_{4} \mathrm{MNPs}$. The EDX spectrum also illustrates other elements including Fe, $\mathrm{S}, \mathrm{Si}, \mathrm{C}$ and $\mathrm{N}$ which are existent in the catalyst substrate.

This survey is aimed to report the efficient and rapid production of polysubstituted pyrrole and 1,2,4,5-tetrasubstituted imidazoles derivatives using lower loading of the very recently introduced nanocatalyst, i.e., $\mathrm{Cu@imine} / \mathrm{Fe}_{3} \mathrm{O}_{4} \mathrm{MNPs}$, under solvent-free conditions. The catalytic activity of $\mathrm{Cu@i-}$ mine/ $/ \mathrm{Fe}_{3} \mathrm{O}_{4}$ MNPs was investigating to report the efficient and rapid production of polysubstituted pyrrole derivatives under solvent-free conditions. To achieve the optimum conditions 


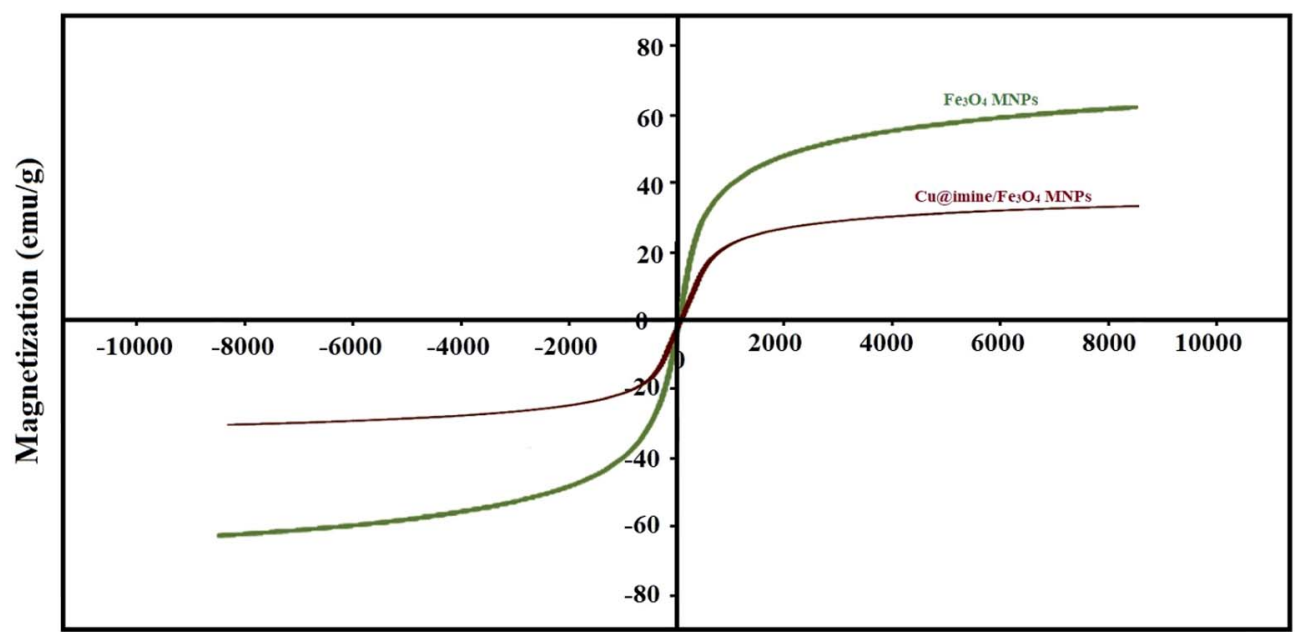

Applied field (Oe)

Fig. 3 Magnetization curves of $\mathrm{Fe}_{3} \mathrm{O}_{4}$ and Cu@imine/ $/ \mathrm{Fe}_{3} \mathrm{O}_{4}$ MNPs.

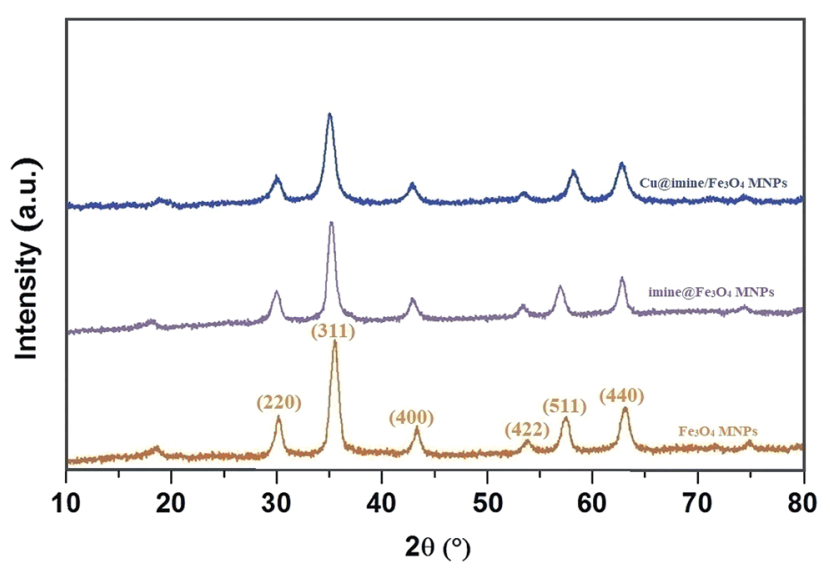

Fig. 4 The XRD patterns of $\mathrm{Fe}_{3} \mathrm{O}_{4}$, iminea $\mathrm{Fe}_{3} \mathrm{O}_{4}$ MNPs, Cuaimine/ $\mathrm{Fe}_{3} \mathrm{O}_{4}$ MNPs.

especially in agreement with green chemistry, the reaction between ethyl acetoacetate, nitromethane, benzaldehyde, and aniline with $1: 1: 1: 1$ molar ratios were selected as the model reactions for synthesizing polysubstituted pyrrole to examine the impacts of the amount of used catalyst, solvent, and temperature. The results of the optimization reactions were presented in Table 1 . The outcomes were evaluated qualitatively using thin layer chromatography (TLC). As observed, in polar organic solvents such as ethanol and acetonitrile, under reflux conditions, the reaction yield was good in long reaction times (Table 1, Entries 1-2). In order to improve the eco-friendly of the reaction conditions, the reaction was occurred in water, but this solvent wasn t observed to be effective and only $37 \%$ of product was achieved after $70 \mathrm{~min}$ (Table 1, Entry 3). Finally, the reaction was performed in non-polar organic solvents such as dichloromethane, chloroform and tetrahydrofuran under reflux conditions, but none of these solvents were observed to be impressive (Table 1, Entries 4-6). The outcomes presented that when the reaction was performed under solvent-free conditions at $100{ }^{\circ} \mathrm{C}$, the target product afforded in best optimal conditions in terms of rate and yield (Table 1, Entry 7). Due to the key role of the catalyst amount as a significant factor for a reaction, we studied the catalytic performance of the $\mathrm{Cu@imine/} / \mathrm{Fe}_{3} \mathrm{O}_{4}$

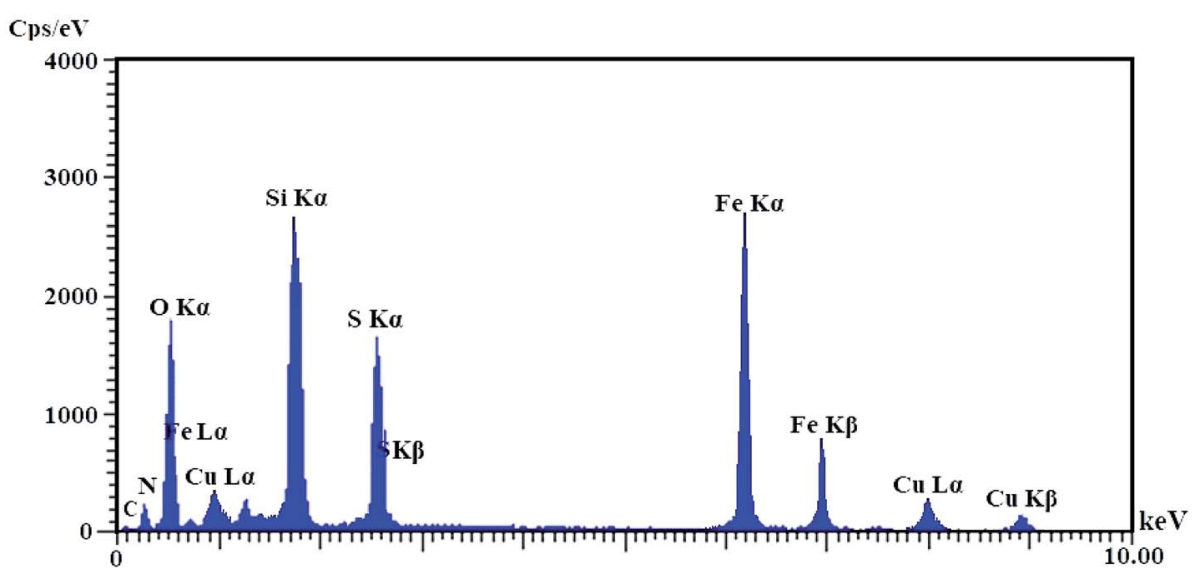

Fig. 5 EDX spectra of Cuaimine/ $/ \mathrm{Fe}_{3} \mathrm{O}_{4} \mathrm{MNPs}$. 
Table 1 Optimization corresponding to the four-component reaction for ethyl acetoacetate, nitromethane, benzaldehyde, and aniline under various conditions ${ }^{a}$

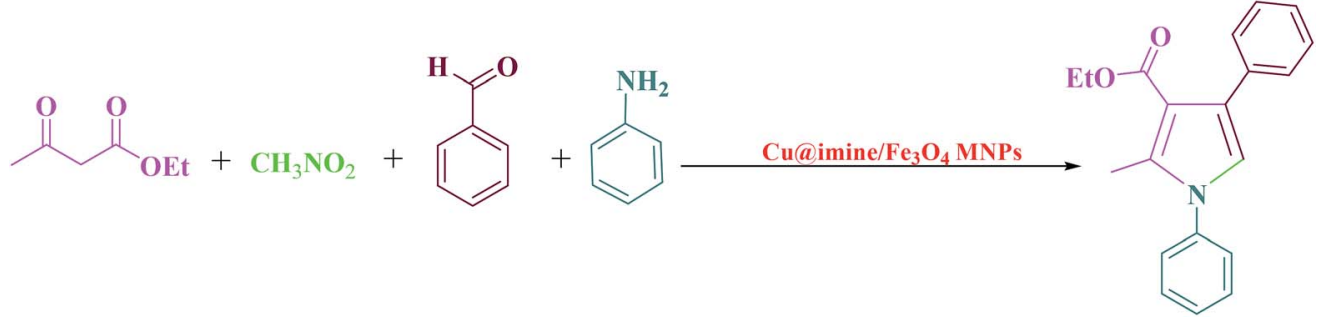

\begin{tabular}{|c|c|c|c|c|c|}
\hline Entry & Solvent & Catalyst (mol\%) & Temp. & Time (min) & Yield $^{b}(\%)$ \\
\hline 1 & Ethanol & 0.36 & Reflux & 50 & 79 \\
\hline 2 & Acetonitrile & 0.36 & Reflux & 50 & 71 \\
\hline 3 & Water & 0.36 & Reflux & 70 & 37 \\
\hline 4 & Dichloromethane & 0.36 & Reflux & 70 & 52 \\
\hline 5 & Chloroform & 0.36 & Reflux & 70 & 56 \\
\hline 6 & Tetrahydrofuran & 0.36 & Reflux & 70 & 49 \\
\hline 7 & Solvent-free & 0.36 & $100{ }^{\circ} \mathrm{C}$ & 25 & 95 \\
\hline 8 & Solvent-free & 0.24 & $100{ }^{\circ} \mathrm{C}$ & 45 & 76 \\
\hline 9 & Solvent-free & 0.48 & $100{ }^{\circ} \mathrm{C}$ & 30 & 94 \\
\hline 10 & Solvent-free & - & $100{ }^{\circ} \mathrm{C}$ & 70 & Trace \\
\hline 11 & Solvent-free & 0.36 & $25^{\circ} \mathrm{C}$ & 70 & 31 \\
\hline 12 & Solvent-free & 0.36 & $60^{\circ} \mathrm{C}$ & 40 & 82 \\
\hline 13 & Solvent-free & 0.36 & $70{ }^{\circ} \mathrm{C}$ & 35 & 85 \\
\hline 14 & Solvent-free & 0.36 & $80^{\circ} \mathrm{C}$ & 35 & 88 \\
\hline 15 & Solvent-free & 0.36 & $90^{\circ} \mathrm{C}$ & 30 & 92 \\
\hline 16 & Solvent-free & 0.36 & $110^{\circ} \mathrm{C}$ & 25 & 93 \\
\hline 17 & Solvent-free & 0.36 & $120^{\circ} \mathrm{C}$ & 25 & 91 \\
\hline 18 & Solvent-free & $\mathrm{BF}_{3}-\mathrm{SiO}_{2} / 0.36$ & $100^{\circ} \mathrm{C}$ & 120 & 71 \\
\hline 19 & Solvent-free & $\mathrm{MgCl}_{2} / 0.36$ & $100{ }^{\circ} \mathrm{C}$ & 90 & 59 \\
\hline 20 & Solvent-free & $\mathrm{SbCl}_{5}-\mathrm{SiO}_{2} / 0.36$ & $100{ }^{\circ} \mathrm{C}$ & 100 & 62 \\
\hline
\end{tabular}

${ }^{a}$ Reaction conditions: ethyl acetoacetate $(1 \mathrm{mmol})$, nitromethane $(1 \mathrm{mmol})$, benzaldehyde $(1 \mathrm{mmol})$, aniline $(1 \mathrm{mmol})$, and the required amount of catalyst. ${ }^{b}$ The yields represent the separated product.

MNPs using $0.24-0.48 \mathrm{~mol} \%$ of the catalyst under solvent-free conditions (Table 2, Entries 7-9), and the yield has increased remarkably in the existence of $0.36 \mathrm{~mol} \%$ of catalyst, whereas the reaction time has decreased (Table 2, Entry 7). By reducing the value of catalyst to $0.24 \mathrm{~mol} \%$, the performance of the product was dropped (Table 1, Entry 8). It was observed that the reaction yield was remained unchanged even in quantities more than the optimum catalyst amount, and $0.48 \mathrm{~mol} \%$ of the catalyst could not cause the obvious increase in yield of the product (Table 1, Entry 9). When the reaction was surveyed without using the catalyst, no formation of product was found in this case (Table 1, Entry 10). To complete the reaction, effect of temperature on the rate of model reaction was investigated by diverse temperatures from room temperature to $120{ }^{\circ} \mathrm{C}$ under solvent-free conditions (Table 1, Entries 11-17). It was observed that the yield of the product increases significantly by increasing the temperature from room temperature to $100{ }^{\circ} \mathrm{C}$ (Table 1, Entries 7 and 11-15), but a further enhance in temperature did not demonstrate any significant impact on the product yield (Table 1, Entries 16-17). It should be noted that when the reaction was carried out in the presence of metal halides (Table 3, Entries 18-20), low to moderate yields of the desired product was obtained.

After optimization of the reaction conditions and to establish the effectiveness and the acceptability of the technique, we explored the scope and generalization of the reaction with a wide range of aldehydes and amines including benzylamine, aniline and substituted anilines under the optimal conditions. The outcomes were listed in Table 2. It was observed that under similar conditions, a variety of benzaldehydes containing electron-withdrawing and electron-donating groups, such as $\mathrm{H}$, $\mathrm{CH}_{3}, \mathrm{CH}_{3} \mathrm{O}, \mathrm{NO}_{2}$ and $\mathrm{Cl}$ in the para positions of the benzene ring as well as heteroaromatic aldehydes in the existence of methyl acetoacetate, nitromethane, benzylamine, and the required amount of the $\mathrm{Cu}$ @imine/ $\mathrm{Fe}_{3} \mathrm{O}_{4}$ MNPs, simply converted to the resulted products in short reaction times with good to excellent isolated yields (Table 2, Entries 1-7). Also, using above aromatic aldehydes, ethyl acetoacetate, nitromethane and aniline the target products were achieved in good to high separated yields (Table 2, Entries 8-11). Various aromatic aldehydes containing electron-withdrawing and electron-donating groups $\left(\mathrm{H}, \mathrm{CH}_{3}, \mathrm{CH}_{3} \mathrm{O}\right.$, and $\left.\mathrm{Cl}\right)$ and anilines 
Table 2 Preparation of polysubstituted pyrrole derivatives using Cu@imine/ $/ \mathrm{Fe}_{3} \mathrm{O}_{4} \mathrm{MNPs}$ as a catalyst ${ }^{a}$

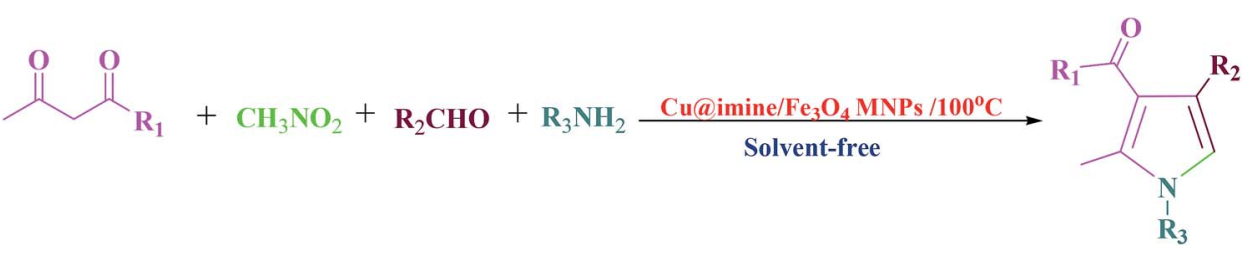

\begin{tabular}{|c|c|c|c|c|c|c|c|c|c|c|}
\hline Entry & $\mathrm{R}_{2} \mathrm{CHO}(3)$ & $\mathrm{R}_{1}$ & $\mathrm{R}_{3}$ & Product & Time (min) & Yield (\%) & $\mathrm{TON}^{b}$ & $\operatorname{TOF}^{c}\left(h^{-1}\right)$ & $\mathrm{Mp}$ (obsd) $\left({ }^{\circ} \mathrm{C}\right)$ & $\mathrm{Mp}(\mathrm{lit})\left({ }^{\circ} \mathrm{C}\right)$ \\
\hline 1 & $\mathrm{C}_{6} \mathrm{H}_{5}^{-}$ & $\mathrm{OMe}$ & $\mathrm{Ph}-\mathrm{CH}_{2}-$ & $5 a$ & 20 & 93 & 258 & 774 & Oil & $\mathrm{Oil}^{27}$ \\
\hline 2 & 4-Cl- $\mathrm{C}_{6} \mathrm{H}_{4}^{-}$ & OMe & $\mathrm{Ph}-\mathrm{CH}_{2}-$ & $5 b$ & 15 & 95 & 264 & 1056 & Oil & $\mathrm{Oil}^{28}$ \\
\hline 4 & $4-\mathrm{CH}_{3}-\mathrm{C}_{6} \mathrm{H}_{4}-$ & $\mathrm{OMe}$ & $\mathrm{Ph}-\mathrm{CH}_{2}-$ & $5 d$ & 20 & 91 & 253 & 759 & Oil & $\mathrm{Oil}^{28}$ \\
\hline 5 & $4-\mathrm{OCH}_{3}-\mathrm{C}_{6} \mathrm{H}_{4-}$ & OMe & $\mathrm{Ph}-\mathrm{CH}_{2}^{-}$ & $5 e$ & 15 & 92 & 256 & 1024 & Oil & $\mathrm{Oil}^{27}$ \\
\hline 6 & 2-Furyl- & OMe & $\mathrm{Ph}-\mathrm{CH}_{2}-$ & $5 f$ & 20 & 94 & 261 & 783 & $128-131$ & 130-132 (ref. 30) \\
\hline 9 & $4-\mathrm{NO}_{2}-\mathrm{C}_{6} \mathrm{H}_{4}-$ & OEt & $\mathrm{Ph}-\mathrm{CH}_{2}-$ & $5 \mathbf{i}$ & 20 & 95 & 264 & 792 & Oil & $\mathrm{Oil}^{29}$ \\
\hline 10 & $4-\mathrm{CH}_{3}-\mathrm{C}_{6} \mathrm{H}_{4}-$ & OEt & $\mathrm{Ph}-\mathrm{CH}_{2}-$ & $5 \mathbf{j}$ & 20 & 91 & 253 & 759 & Oil & $\mathrm{Oil}^{27}$ \\
\hline 11 & $4-\mathrm{OCH}_{3}-\mathrm{C}_{6} \mathrm{H}_{4}-$ & OEt & $\mathrm{Ph}-\mathrm{CH}_{2}-$ & $5 k$ & 20 & 89 & 247 & 741 & Oil & $\mathrm{Oil}^{29}$ \\
\hline 12 & $\mathrm{C}_{6} \mathrm{H}_{5^{-}}$ & OEt & $\mathrm{C}_{6} \mathrm{H}_{5^{-}}$ & 51 & 25 & 95 & 264 & 634 & Oil & $\mathrm{Oil}^{31}$ \\
\hline 13 & $4-\mathrm{Cl}-\mathrm{C}_{6} \mathrm{H}_{4}^{-}$ & OEt & $\mathrm{C}_{6} \mathrm{H}_{5}^{-}$ & $5 \mathrm{~m}$ & 20 & 90 & 250 & 750 & $126-128$ & 127-129 (ref. 32) \\
\hline 14 & $4-\mathrm{CH}_{3}-\mathrm{C}_{6} \mathrm{H}_{4}-$ & OEt & $4-\mathrm{Cl}-\mathrm{C}_{6} \mathrm{H}_{4}-$ & $5 n$ & 20 & 91 & 253 & 759 & $119-122$ & $120-122$ (ref. 32) \\
\hline
\end{tabular}

${ }^{a}$ Reaction conditions: ethyl acetoacetate $(1 \mathrm{mmol})$, nitromethane $(1 \mathrm{mmol})$, benzaldehyde $(1 \mathrm{mmol})$, and aniline $\left.(1 \mathrm{mmol})\right)$ and Cu@imine/Fe $\mathrm{O}_{4}$ MNPs $(0.36 \mathrm{~mol} \%)$ at $100{ }^{\circ} \mathrm{C} .{ }^{b}$ Number of moles of product produced from 1 mole of catalyst. ${ }^{c}$ TON per unit of time.

Table 3 Optimization of the four-component reaction of benzil, benzaldehyde, benzylamine and ammonium acetate under various conditions ${ }^{a}$

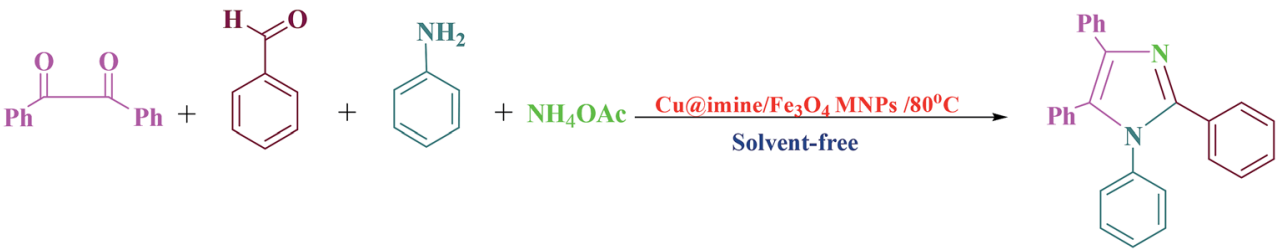

\begin{tabular}{|c|c|c|c|c|c|}
\hline Entry & Solvent & Catalyst (mol\%) & Temp. & Time (min) & Yield $^{b}(\%)$ \\
\hline 1 & Ethanol & 0.36 & Reflux & 55 & 69 \\
\hline 2 & Acetonitrile & 0.36 & Reflux & 55 & 61 \\
\hline 4 & Dichloromethane & 0.36 & Reflux & 70 & 45 \\
\hline 5 & Chloroform & 0.36 & Reflux & 70 & 49 \\
\hline 6 & Tetrahydrofuran & 0.36 & Reflux & 70 & 43 \\
\hline 9 & Solvent-free & 0.48 & $80^{\circ} \mathrm{C}$ & 35 & 92 \\
\hline 10 & Solvent-free & 0.36 & $25^{\circ} \mathrm{C}$ & 120 & 35 \\
\hline 11 & Solvent-free & 0.36 & $60{ }^{\circ} \mathrm{C}$ & 65 & 69 \\
\hline 12 & Solvent-free & 0.36 & $70{ }^{\circ} \mathrm{C}$ & 45 & 75 \\
\hline 13 & Solvent-free & 0.36 & $90^{\circ} \mathrm{C}$ & 35 & 93 \\
\hline 14 & Solvent-free & 0.36 & $100^{\circ} \mathrm{C}$ & 35 & 91 \\
\hline
\end{tabular}

${ }^{a}$ Reaction conditions: benzil ( $\left.1 \mathrm{mmol}\right)$, benzaldehyde ( $\left.1 \mathrm{mmol}\right)$, benzylamine ( $\left.1 \mathrm{mmol}\right)$, ammonium acetate ( 4 mmol), and the required amount of catalyst. ${ }^{b}$ The yields refer to the separated product. 
with the above-mentioned substituted electron-withdrawing and electron-donating groups in the para positions of the benzene ring were efficiently reacted with ethyl acetoacetate and nitromethane in excellent yields and times (Table 2, Entries 1216).

To obtain the optimize reaction conditions of the production of 1,2,4,5-tetrasubstituted imidazoles derivatives, the reaction between benzil, benzylamine, benzaldehyde and ammonium acetate with 1 : 1 : 1 : 4 molar ratios using $0.36 \mathrm{~mol} \%$ of catalyst was examined in the existence of diverse solvents, the concentration of used catalyst, and temperatures. To find the solvent effect, the reaction was carried out in the existence of various polar and non-polar solvents such as ethanol, acetonitrile, water, dichloromethane, chloroform and tetrahydrofuran. When water was applied as a solvent, the reaction proceeded smoothly for producing the desired product (5a) in good yield (Table 3, Entry 3). The model reaction in the rest of the solvents mentioned above demanded long reaction times, and provided the product $5 \mathrm{a}$ in poor to moderate yields (Table 1, Entries 1-2 and 4-6). Interestingly, none of these solvents were impressive and the model reaction proceeded rapidly to obtain the desired product in excellent yield 95\% under solvent-free conditions (Table 3, Entry 7). Over optimizing the reaction conditions, the impact of catalytic activity of the $\mathrm{Cu}$ @imine/ $\mathrm{Fe}_{3} \mathrm{O}_{4}$ MNPs on the model reaction was also studied at $0.24,0.36$, and $0.48 \mathrm{~mol} \%$ to test their efficiency under solvent-free conditions (Table 3, Entries 7-9). It was observed that the product yield has increased in the existence of $0.36 \mathrm{~mol} \%$ of catalyst (Table 3, Entry 7). Hence, $0.36 \mathrm{~mol} \%$ was chosen as optimum catalyst amount for the reaction. Following choice of the optimal concentration of catalyst, the effect of the temperature on yield of the model reaction was evaluated by diverse temperatures from room temperature to $100{ }^{\circ} \mathrm{C}$ in the existence of required amount of catalysts under solvent-free conditions (Table 3, Entries 7 and 10-14). It was found that by raising the reaction temperature, yield of the product increases. Maximum yield (95\%) was obtained when the temperature of $80{ }^{\circ} \mathrm{C}$ was applied to the reaction system (Table 3, Entry 7). Further rise in the temperature had no considerable impact on the product yield (Table 3, Entries 13-14). It should be mentioned that the product yield has decreased remarkably at temperatures below $80{ }^{\circ} \mathrm{C}$, whereas the reaction time has increased (Table 3, Entries 10-12). Therefore, as shown in Table 3, using $0.36 \mathrm{~mol} \%$ of $\mathrm{Cu}$ @imine/ $\mathrm{Fe}_{3} \mathrm{O}_{4} \mathrm{MNPs}$ under solvent-free and $80{ }^{\circ} \mathrm{C}$ gave the maximum yield of the target product in the shortest time. It is noteworthy that when the reaction was carried out in the presence of metal halides (Table 3, Entries 15-17), low to moderate yields of the desired product was obtained.

With the optimized condition in hand, we explored the scope and generalization of the catalyst over a variety of aldehydes and amines as substrates for synthesizing 1,2,4,5-tetrasubstituted imidazoles. The outcomes were presented in Table 4 . These results illustrates that the reactions are similarly facile with both electron-withdrawing and electron-donating groups, such as $\mathrm{H}, \mathrm{CH}_{3}, \mathrm{CH}_{3} \mathrm{O}, \mathrm{NO}_{2}$ and $\mathrm{Cl}$ in the meta and para positions of the benzene ring and amines, causing good to high yields of the relating imidazoles.

A proposed mechanism of the synthesis of replaced imidazoles catalyzed by $\mathrm{Cu}$ @imine $/ \mathrm{Fe}_{3} \mathrm{O}_{4}$ MNPs is depicted in Scheme 2. In the beginning, carbonyl oxygen of aldehyde is coordinated to copper center on the nanocomposites surface to generate a better electrophilic species which more readily reacts with amine to give diamine intermediate 6. The next step involves formation of imino intermediate 7 by condensing

Table 4 Preparation of 1,2,4,5-tetrasubstituted imidazoles derivatives using Cu@imine/Fe $\mathrm{O}_{4} \mathrm{MNPs}$ as a catalyst ${ }^{a}$

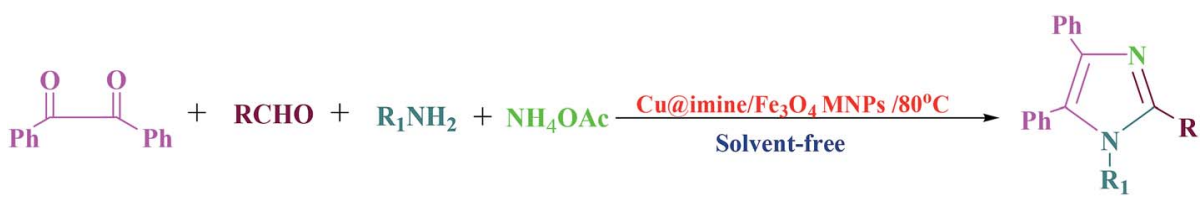

\begin{tabular}{|c|c|c|c|c|c|c|c|c|c|}
\hline Entry & RCHO (2) & $\mathrm{R}_{1}$ & Product & Time (min) & Yield (\%) & $\mathrm{TON}^{b}$ & $\operatorname{TOF}^{c}\left(\mathrm{~h}^{-1}\right)$ & $\mathrm{Mp}$ (obsd) $\left({ }^{\circ} \mathrm{C}\right)$ & $\mathrm{Mp}(\mathrm{lit})\left({ }^{\circ} \mathrm{C}\right)$ \\
\hline 1 & $\mathrm{C}_{6} \mathrm{H}_{5}^{-}$ & $\mathrm{C}_{6} \mathrm{H}_{5}^{-}$ & $5 a$ & 35 & 95 & 264 & 453 & $215-217$ & 216-218 (ref. 33) \\
\hline 2 & $4-\mathrm{Cl}-\mathrm{C}_{6} \mathrm{H}_{4^{-}}$ & $\mathrm{C}_{6} \mathrm{H}_{5^{-}}$ & $5 \mathbf{b}$ & 30 & 95 & 264 & 528 & $150-152$ & 149-151 (ref. 33) \\
\hline 4 & $4-\mathrm{CH}_{3}-\mathrm{C}_{6} \mathrm{H}_{4}-$ & $\mathrm{C}_{6} \mathrm{H}_{5}^{-}$ & $5 d$ & 35 & 93 & 258 & 442 & $186-188$ & 185-188 (ref. 33) \\
\hline 5 & $4-\mathrm{OCH}_{3}-\mathrm{C}_{6} \mathrm{H}_{4}^{-}$ & $\mathrm{C}_{6} \mathrm{H}_{5^{-}}$ & $5 e$ & 35 & 92 & 256 & 439 & $170-172$ & 171-173 (ref. 35) \\
\hline 6 & $3,4-\left(\mathrm{OCH}_{3}\right)_{2}-\mathrm{C}_{6} \mathrm{H}_{4}^{-}$ & $\mathrm{C}_{6} \mathrm{H}_{5^{-}}$ & $5 f$ & 35 & 94 & 261 & 447 & $173-176$ & 175-178 (ref. 35) \\
\hline 9 & $4-\mathrm{NO}_{2}-\mathrm{C}_{6} \mathrm{H}_{4^{-}}$ & $n-\mathrm{Pr}-\mathrm{NH}_{2}$ & $5 \mathbf{i}$ & 20 & 98 & 272 & 816 & $159-162$ & 161-163 (ref. 37) \\
\hline 10 & $3-\mathrm{NO}_{2}-\mathrm{C}_{6} \mathrm{H}_{4}-$ & $n-\mathrm{Pr}-\mathrm{NH}_{2}$ & $5 \mathbf{j}$ & 20 & 98 & 272 & 816 & 139-141 & 141-142 (ref. 37) \\
\hline 11 & $4-\mathrm{CH}_{3}-\mathrm{C}_{6} \mathrm{H}_{4}-$ & $n-\mathrm{Pr}-\mathrm{NH}_{2}$ & $5 k$ & 25 & 93 & 258 & 619 & $80-83$ & 78-83 (ref. 36) \\
\hline 12 & $\mathrm{C}_{6} \mathrm{H}_{5^{-}}$ & $4-\mathrm{EtC}_{6} \mathrm{H}_{4}$ & 51 & 35 & 96 & 266 & 456 & $141-143$ & $142-144$ (ref. 37) \\
\hline 13 & $3-\mathrm{NO}_{2}-\mathrm{C}_{6} \mathrm{H}_{4}-$ & $4-\mathrm{EtC}_{6} \mathrm{H}_{4}$ & $5 \mathrm{~m}$ & 25 & 98 & 272 & 653 & $130-133$ & 131-132 (ref. 37) \\
\hline 14 & $4-\mathrm{CH}_{3}-\mathrm{C}_{6} \mathrm{H}_{4}-$ & $4-\mathrm{EtC}_{6} \mathrm{H}_{4}$ & $5 n$ & 35 & 94 & 261 & 447 & $157-160$ & 159-161 (ref. 37) \\
\hline
\end{tabular}

${ }^{a}$ Reaction conditions: benzil (1 mmol), benzaldehyde (1 mmol), benzylamine (1 mmol), ammonium acetate (4 mmol) and Cu@imine $/ \mathrm{Fe}_{3} \mathrm{O}_{4} \mathrm{MNPs}$ $(0.36 \mathrm{~mol} \%)$ at $80{ }^{\circ} \mathrm{C} .{ }^{b}$ Number of moles of product produced from 1 mole of catalyst. ${ }^{c}$ TON per unit of time. 


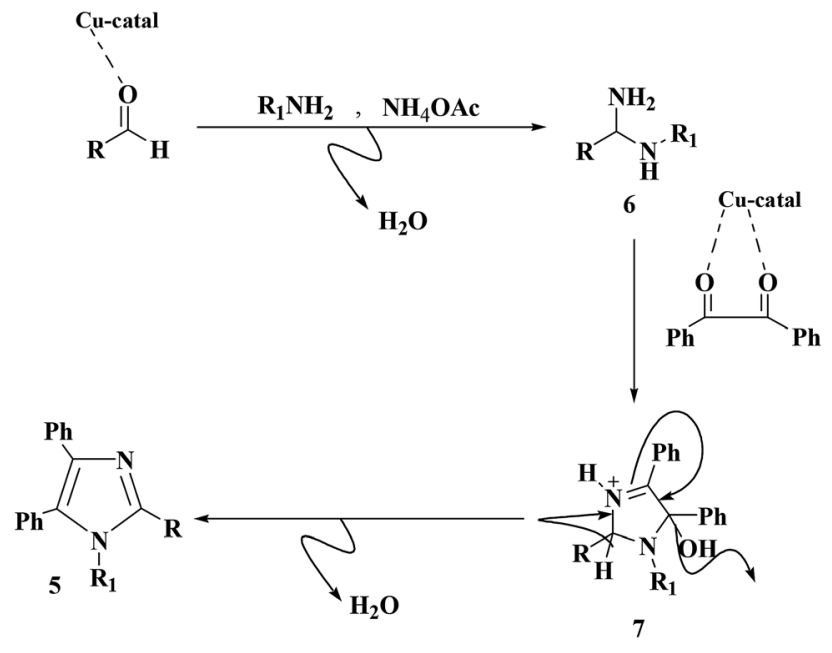

Scheme 2 A plausible mechanism of the creation of 1,2,4,5-tetrasubstituted imidazoles derivatives in the existence of Cu@imine/ $\mathrm{Fe}_{3} \mathrm{O}_{4}$ MNPs under solvent-free conditions.

diamine with 1,2-diketone, followed by dehydrating the relating products 5 .

The mechanism corresponding to production of greatly

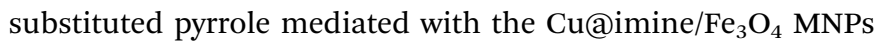
catalyst was presented in Scheme 3. The reaction occurs via initial production of the enamine 6 by nucleophilic addition of amine to b-ketoester followed by dehydration. Then, nitromethane reacts with aldehyde to generate intermediate 7 . Subsequently, the enamine 6 reacts with intermediate 7 to afford Michael adduct 8. Following intramolecular nucleophilic cyclization by dehydration delivers the desired pyrrole.

Recycling and recoverability of the Cu@imine $/ \mathrm{Fe}_{3} \mathrm{O}_{4}$ MNPs were evaluated in the reaction between ethylacetoacetate, nitromethane, benzaldehyde, and aniline. At the end of the reaction, $10 \mathrm{~mL}$ hot mixture of ethyl acetate and ethanol $(4: 10$ ratio) was poured in to the reaction solution to dissolve the raw product. Then, the catalyst was isolated from the reaction

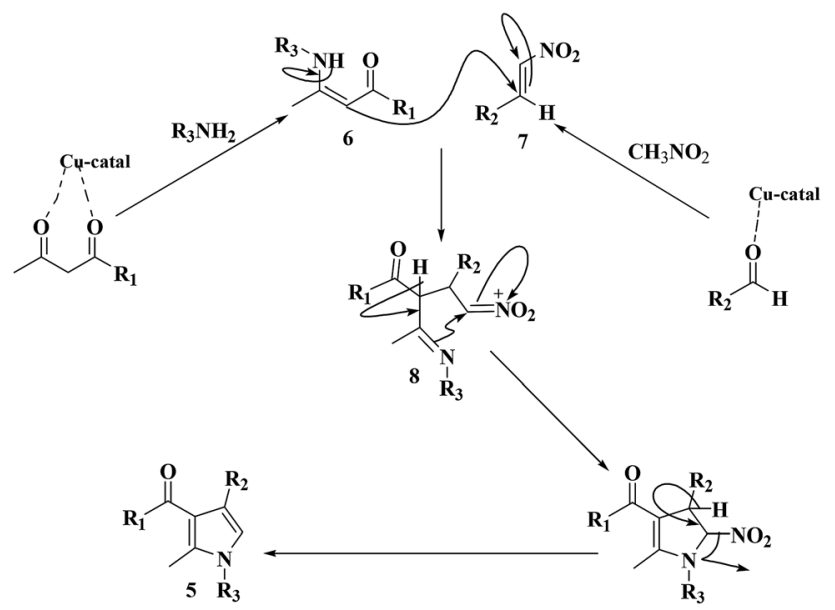

Scheme 3 A plausible mechanisms for the creation of polysubstituted pyrrole derivatives in the existence of Cuaimine/ $/ \mathrm{Fe}_{3} \mathrm{O}_{4} \mathrm{MNPs}$ under solvent-free conditions.

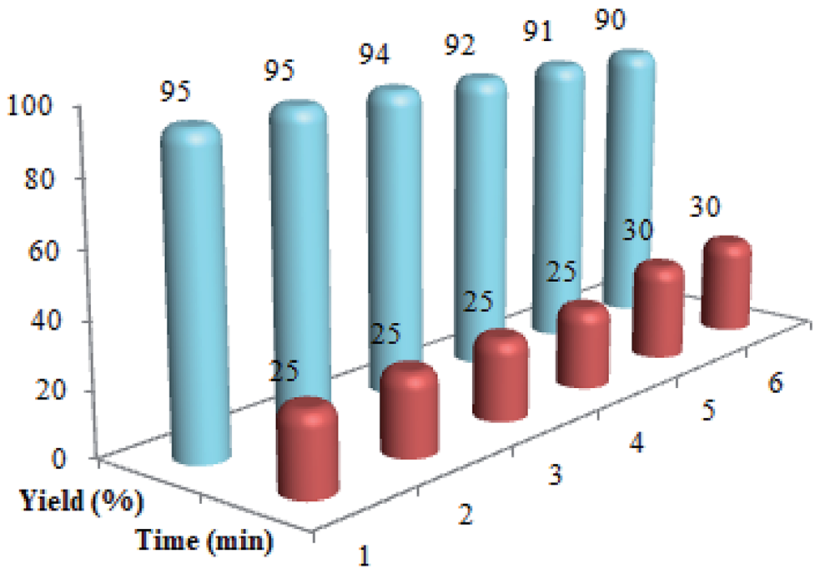

Fig. 6 The recycling of Cu@imine/ $\mathrm{Fe}_{3} \mathrm{O}_{4}$ MNPs in the preparation of polysubstituted pyrrole derivatives.

solution by a permanent magnet, washed with chloroform, dried and recovered for a minimum of six runs (Fig. 6).

To evaluate recycling and recoverability of the Cu@imine/ $\mathrm{Fe}_{3} \mathrm{O}_{4}$ MNPs, after six periods of recycling, this catalyst was reused in the reaction of benzil, benzaldehyde, benzylamine and ammonium acetate under the optimal reaction conditions (Fig. 7). To achieve this purpose, at the end of the reaction, a hot mixture of ethyl acetate and ethanol ( $4: 10$ ratio) was added to the reaction solution and then the catalyst was removed simply by means of a permanent external magnet. The recovered Cu@imine/ $\mathrm{Fe}_{3} \mathrm{O}_{4}$ MNPs was rinsed with chloroform, dried, and recovered for alternative reaction.

Table 5 shows the efficiency of $\mathrm{Cu} @ i m i n e / \mathrm{Fe}_{3} \mathrm{O}_{4}$ MNPs as the novel heterogeneous magnetic nanocatalyst in preparing 1benzyl-4-(4-chloro-phenyl)-2-methyl-1 $H$-pyrrole-3-carboxylic acid methyl ester and 1,2,4,5-tetraphenyl- $1 H$-imidazole compared with those obtained by some of the other reported homogeneous and heterogeneous catalysts. As clearly shown in Table 5, although all the reported catalysts can catalyze the reactions, most of them suffer from one or more disadvantages, such as long reaction times, low yields of the products, use of toxic catalyst, tedious work-up procedures, and high catalyst

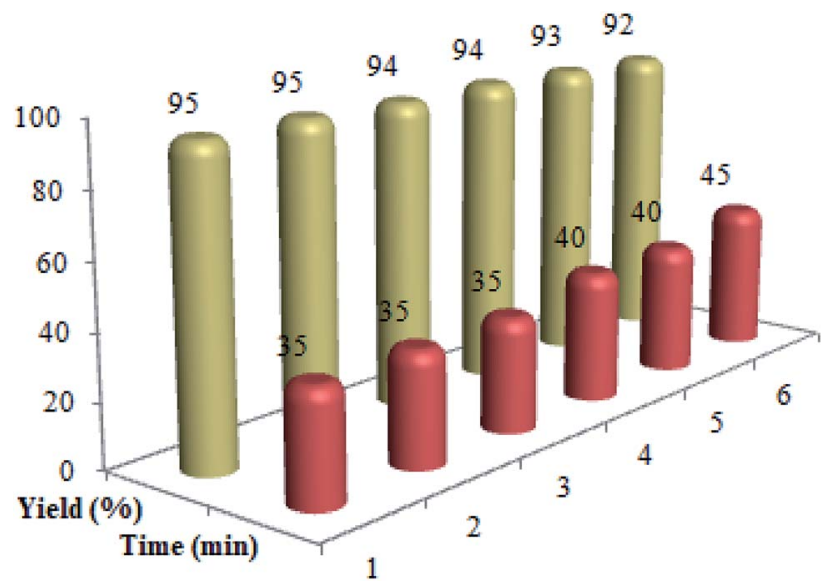

Fig. 7 The recycling of Cuaimine/ $\mathrm{Fe}_{3} \mathrm{O}_{4} \mathrm{MNPS}$ in the synthesis of 1,2,4,5-tetrasubstituted imidazoles derivatives. 
Table 5 Comparison of the current methods with other reported strategies for synthesizing 1-benzyl-4-(4-chloro-phenyl)-2-methyl-1Hpyrrole-3-carboxylic acid methyl ester and 1,2,4,5-tetraphenyl- $1 \mathrm{H}$-imidazole derivatives

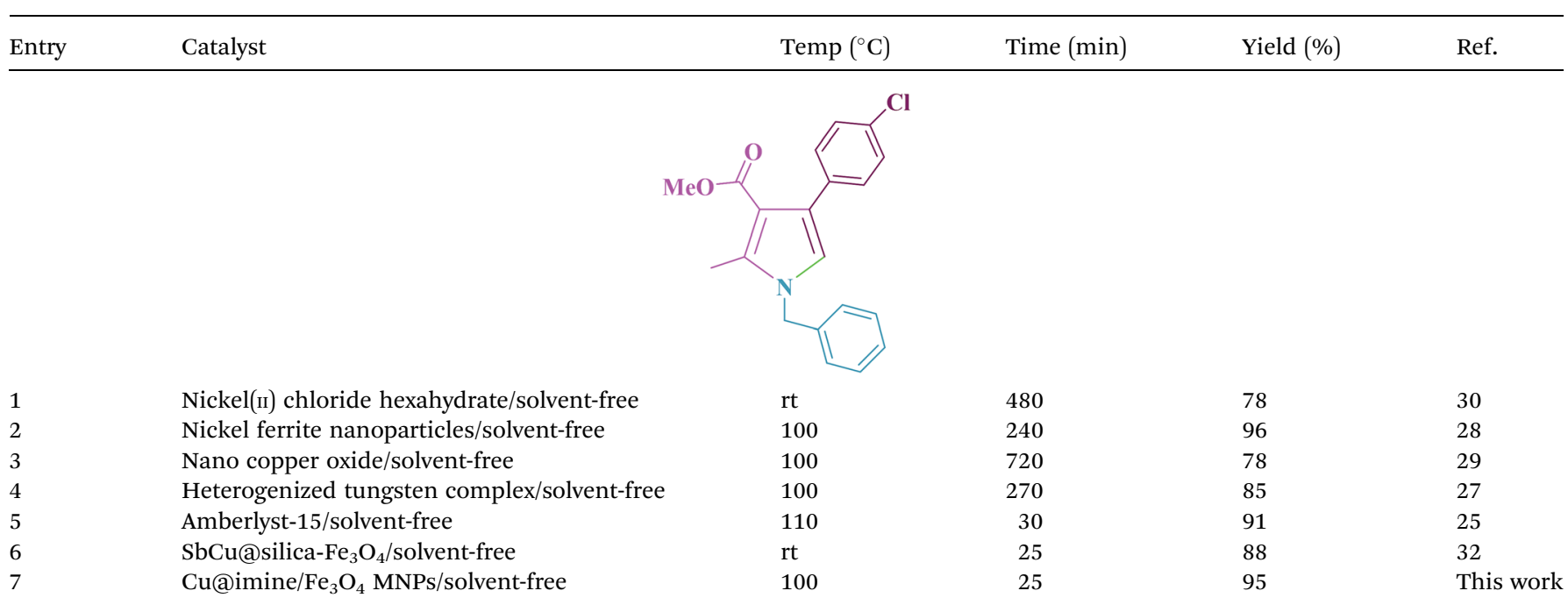

$\mathrm{BF}_{3} / \mathrm{SiO}_{2} /$ solvent-free

$\mathrm{TiCl}_{4} / \mathrm{SiO}_{2} /$ solvent-free

Glycerol as solvent

PEG-400 as a solvent

$\mathrm{NaH}_{2} \mathrm{PO}_{4}$ /solvent-free

$\mathrm{Fe}_{3} \mathrm{O}_{4}$-PEG-Cu/solvent-free

$\gamma-\mathrm{Fe}_{2} \mathrm{O}_{3} @ \mathrm{TiO}_{2}-\mathrm{EG}-\mathrm{Cu}(\mathrm{II}) /$ solvent-free

$\mathrm{Cu} @ i m i n e / \mathrm{Fe}_{3} \mathrm{O}_{4} \mathrm{MNPs} /$ solvent-free

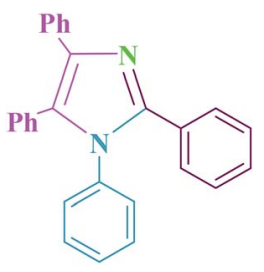

loading. For these reasons, the catalytic behaviour of our catalytic system is significant in terms of easy work-up procedures, low catalyst loading, low reaction times, and simple recovery of the catalyst.

\section{Conclusion}

We have described a simple, facile, and effective process for the eco-friendly and fast production of biologically active polysubstituted pyrroles and 1,2,4,5-tetrasubstituted imidazoles derivatives. The reaction system was significantly affected by catalyst loading and reaction temperature. The catalyst could be recovered and reused at least six times without any significant decrease in its activity. The attractive properties of this procedure are short reaction times, simple workup, high yields, reusability and re-activity of the catalyst as well as simple purification of the products.

\section{Conflicts of interest}

There are no conflicts to declare.

\section{Acknowledgements}

The results were obtained in the framework of the implementation of the initiative scientific project No. 40.5084.2017/ $\mathrm{BCH}$ "Study of methods and modeling processes in biotechnology and plant systematics".

\section{References}

1 K. Niknam and D. Saberi, Tetrahedron Lett., 2009, 50, 5210. 2 X. Liu, X. Zhao and M. Lu, Catal. Lett., 2015, 145, 1549.

3 M. Hosseini-Sarvari, A. Khanivar and F. Moeini, J. Iran. Chem. Soc., 2016, 13, 45.

4 L. Shiri, A. Ghorbani-Choghamarani and M. Kazemi, Aust. J. Chem., 2016, 69, 585.

5 B. Karami, S. J. Hoseini, K. Eskandari, A. Ghasemi and H. Nasrabadi, Catal. Sci. Technol., 2012, 2, 331.

6 A. L. Morel, S. I. Nikitenko, K. Gionnet, A. Wattiaux, J. LaiKee-Him, C. Labrugere, B. Chevalier, G. Deleris, C. Petibois, A. Brisson and M. Simonoff, J. Am. Chem. Soc., 2008, 2, 847. 
7 Y. Weia, B. Hanb, X. Hua, Y. Linc, X. Wangd and X. Denga, Procedia Eng, 2012, 27, 632.

8 Y. S. Kim and Y. H. Kim, J. Magn. Magn. Mater., 2003, 267, 105.

9 M. Nasr-Esfahani, S. J. Hoseyni and F. Mohammadi, Chin. J. Catal., 2011, 23, 1484.

10 H. Koike, T. Konse, T. Sada, T. Ikeda, A. Hyogo, D. Hinman, H. Saito and H. Yanagisawa, Annu. Rep. Sankyo Res. Lab., 2003, 55, 1.

11 S. L. Abrahams, R. J. Hazen, A. G. Batson and A. P. Phillips, J. Pharmacol. Exp. Ther., 1989, 249, 359.

12 C. Leister, Y. Wang, Z. Zhao and C. W. Lindsley, Org. Lett., 2004, 6, 1453.

13 H. Debus, Ann. Chem. Pharm., 1858, 107, 199.

14 B. Radziszewski, Chem. Ber., 1882, 15, 1493.

15 A. Chawla, A. Sharma and A. Kumar, Pharma Chem., 2012, 4, 116.

16 M. Rahman, A. K. Bagdi, D. Kundu, A. Majee and A. Hajra, J. Heterocycl. Chem., 2012, 49, 1224.

17 K. Ramesh, S. N. Murthy, K. Karnakar, Y. V. D. Nageswar, K. Vijayalakhshmi, B. L. A. Prabhavathi Devi and R. B. N. Prasad, Tetrahedron Lett., 2012, 53, 1126.

18 K. Niknam, A. Deris, F. Naeimi and F. Majleci, Tetrahedron Lett., 2011, 52, 4642.

19 A. Hasaninejad, A. Zare, M. Shekouhy and J. A. Rad, J. Comb. Chem., 2010, 12, 844.

20 N. S. Murthy, B. Madhav and Y. V. D. Nageswar, Tetrahedron Lett., 2010, 51, 5252.

21 C. Mukhopadhyay, P. K. Tapaswi and M. G. B. Drew, Tetrahedron Lett., 2010, 51, 3944.

22 P. F. Zhang and Z. C. Z. Chen, Synthesis, 2001, 2075.

23 D. I. Ma Gee, M. Bahramnejad and M. Dabiri, Tetrahedron Lett., 2013, 54, 2591.

24 A. Keivanloo1, M. Bakherad, E. Imanifar and M. Mirzaee, Appl. Catal., A, 2013, 467, 291.
25 P. R. K. Murthi, D. Rambabu, M. V. B. Rao and M. Pal, Tetrahedron Lett., 2014, 55, 507.

26 K. Konkala, R. Chowrasia, P. S. Manjari, N. L. C. Domingues and R. Katla, RSC Adv., 2016, 6, 43339.

27 A. B. Atar and Y. T. Jeong, Tetrahedron Lett., 2013, 54, 5624.

28 F. M. Moghaddam, B. K. Foroushani and H. R. Rezvani, RSC Adv., 2015, 5, 18092.

29 H. Saeidian, M. Abdoli and R. Salimi, C. R. Chim., 2013, 16, 1063.

30 A. T. Khan, M. Lal, P. R. Bagdi, R. S. Basha, P. Saravanan and S. Patra, Tetrahedron Lett., 2012, 53, 4145.

31 N. Gupta, K. N. Singh and J. Singh, J. Mol. Liq., 2014, 199, 470.

32 S. A. Hamrahian, J. Rakhtshah, S. M. Mousavi-Davijani and S. Salehzadeh, Appl. Organomet. Chem., 2018, 35, e4501.

33 B. Sadeghi, B. B. F. Mirjalili, S. Bidaki and M. Ghasemkhani, J. Iran. Chem. Soc., 2011, 8, 648.

34 V. Kannan and K. Sreekumar, J. Mol. Catal. A: Chem., 2013, 376, 34.

35 A. V. Borhade, D. R. Tope and S. G. Gite, Arabian J. Chem., 2017, 10, S559-S567.

36 J. Safari and Z. Zarnegar, C. R. Chim., 2013, 16, 920.

37 Z. Zarnegar and J. Safari, New J. Chem., 2014, 38, 4555.

38 X. C. Wang, H. P. Gong, Z. J. Quan, L. Li and H. L. Ye, Chin. Chem. Lett., 2009, 20, 44.

39 B. Sadeghi, B. B. F. Mirjalili and M. M. Hashemi, Tetrahedron Lett., 2008, 49, 2575.

40 B. F. Mirjalili, A. H. Bamoniri and L. Zamani, Sci. Iran., 2012, 19, 565.

41 F. Nemati, M. M. Hosseini and H. Kiani, J. Saudi Chem. Soc., 2016, 20, S503-S508.

42 Z. Karimi-Jaberi and M. Barekat, Chin. Chem. Lett., 2010, 21, 1183.

43 Z. Zarnegar and J. Safari, New J. Chem., 2014, 38, 4555.

44 M. Nejatianfar, B. Akhlaghinia and R. Jahanshahi, Appl. Organomet. Chem., 2018, 32, 4095. 